\title{
Genetic vulnerability to schizophrenia is associated with cannabis use patterns during adolescence
}

\author{
Marieke Hiemstra $^{\mathrm{a}, *}$, Stefanie A. Nelemans ${ }^{\mathrm{a}, \mathrm{b}}$, Susan Branje ${ }^{\mathrm{a}}$, Kristel R. van Eijk ${ }^{\mathrm{c}}$, \\ Jouke-Jan Hottenga $^{\text {d,e }}$, Christiaan H. Vinkers ${ }^{c}$, Pol van Lier ${ }^{e, f}$, Wim Meeus ${ }^{a, g}$, Marco P. Boks

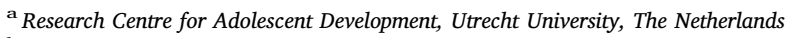 \\ ${ }^{\mathrm{b}}$ Research Group for School Psychology and Child and Adolescent Psychology, KU Leuven, Belgium \\ ${ }^{\mathrm{c}}$ Department of Psychiatry, Brain Center Rudolf Magnus, University Medical Center Utrecht, Utrecht, The Netherlands \\ d Department of Biological Psychology, VU University Amsterdam, The Netherlands \\ ${ }^{\mathrm{e}}$ EMGO Institute for Health and Care Research, The Netherlands \\ ${ }^{\mathrm{f}}$ Department of Clinical Developmental Psychology, VU University Amsterdam, The Netherlands \\ ${ }^{g}$ Department of Developmental Psychology, Tilburg University, The Netherlands
}

\section{A R T I C L E I N F O}

\section{Keywords:}

Adolescence

Schizophrenia

Polygenic risk score

Cannabis use

Smoking

Alcohol use

Substance use

Genetic

\begin{abstract}
A B S T R A C T
Background: Previously reported comorbidity between schizophrenia and substance use may be explained by shared underlying risk factors, such as genetic background. The aim of the present longitudinal study was to investigate how a genetic predisposition to schizophrenia was associated with patterns of substance use (cannabis use, smoking, alcohol use) during adolescence (comparing ages 13-16 with 16-20 years).

Method: Using piecewise latent growth curve modelling in a longitudinal adolescent cohort (RADAR-Y study, $N=372$ ), we analyzed the association of polygenic risk scores for schizophrenia (PRS; p-value thresholds $\left(p_{t}\right)<5$ e-8 to $p_{t}<0.5$ ) with increase in substance use over the years, including stratified analyses for gender. Significance thresholds were set to adjust for multiple testing using Bonferroni at $p \leq 0.001$.

Results: High schizophrenia vulnerability was associated with a stronger increase in cannabis use at age 16-20 (PRS thresholds $p_{t}<5 \mathrm{e}-5$ and $p_{t}<5 \mathrm{e}-4 ; p_{t}<5 \mathrm{e}-6$ was marginally significant), whereas more lenient PRS thresholds (PRS thresholds $p_{t}<5 \mathrm{e}-3$ to $p_{t}<0.5$ ) showed the reverse association. For smoking and alcohol, no clear relations were found.

Conclusions: In conclusion, our findings support a relation between genetic risk to schizophrenia and prospective cannabis use patterns during adolescence. In contrast, no relation between alcohol and smoking was established.
\end{abstract}

\section{Introduction}

During early adolescence, many youths start using alcohol, tobacco, and cannabis after which substance use increases rapidly (e.g., Hibell et al., 2012; Van Laar et al., 2013). At the age of 12 years, 17\% of Dutch adolescents reported lifetime alcohol use (de Looze et al., 2014), 6\% had smoked at least once (Verdurmen et al., 2014) and 0.3\% reported ever using cannabis (Van Laar et al., 2013). By the age of 16, these percentages of substance use had increased to $79.3 \%, 43 \%$, and $26.9 \%$ for lifetime alcohol use, smoking, and cannabis use respectively. In addition to the use of specific substances, the frequency and intensity of use also increase during adolescence. For example, binge drinking in the past month (i.e., drinking five or more glasses on one occasion) increased from $47.2 \%$ at age 12 to $79.9 \%$ at age 16 among adolescents who drink alcohol (de Looze et al., 2014).
Earlier studies of adolescents and young adults have shown an association of mental health problems including schizophrenia, depression, and anxiety disorders, with substance use (e.g., Kendler et al., 2015; Moore et al., 2007; Schubart et al., 2011). More specifically, studies have shown that cannabis use (e.g., Arseneault et al., 2002; Kendler et al., 2015; Moore et al., 2007; Schubart et al., 2011) and cigarette smoking (de Leon and Diaz, 2005; McGrath et al., 2015; van Gastel et al., 2012, 2013) are associated with psychosis proneness. Also, high comorbidity between alcohol dependence and psychiatric disorders, in general, has been reported (e.g., Kessler et al., 1994).

Several possible mechanisms may explain the comorbidity between schizophrenia and substance use (e.g., Gage and Munafo, 2015; Hartz et al., 2018). 1) Substance use may lead to the onset of schizophrenia. 2) Schizophrenia may cause the development of substance addiction (the self-medication hypothesis), and 3) shared underlying risk factors,

\footnotetext{
* Corresponding author at: Research Centre for Adolescent Development, Utrecht University, P.O. Box 80.140, 3508TC Utrecht, The Netherlands.

E-mail address: marieke_hiemstra@hotmail.com (M. Hiemstra).
} 
both environmental and genetic may predispose to schizophrenia and substance use such as is suggested for cannabis (Verweij et al., 2017). In the present study, we focus on the genetic background as the shared underlying risk factor. Genetic risk factors are relevant as both schizophrenia and substance use are heritable. The heritability estimates of schizophrenia are around $80 \%$ for (Sullivan et al., 2003) and 11-84\% for substance use (Verweij et al., 2010; Ho and Tyndale, 2007; Goldman et al., 2005). Moreover, a large number of common variants of small genetic effects are involved in both traits (e.g., Ripke et al., 2013; Tobacco and Genetics Consortium, 2010; Stringer et al., 2016).

To investigate the genetic overlap between schizophrenia and substance use, polygenic risk scores (PRS) based on genome-wide association studies (GWAS) are used (Ripke et al., 2013). PRS is the weighted sum of all the alleles that either confer risk for or are protective against a specific disease (Purcell et al., 2007). PRS can be used to predict individual genetic risk for schizophrenia in a nonpatient sample. More specifically, PRS can be constructed by multiple-testing different sets of single nucleotide polymorphisms (SNPs) selected at various thresholds of significance (i.e., in the present study: $p$-value thresholds $5 \mathrm{e}-8$ to 0.5 were used to investigate the full range of genetic background).

Recent studies have shown a genetic overlap between schizophrenia PRS and substance use, particularly cannabis use. More specifically, an association between schizophrenia genetic risk alleles and cannabis use was found among 2082 adults (mean age 41.3 years for users and 53.0 years for non-users) (Power et al., 2014). Recently, Carey et al. (2016) and Verweij et al. (2017) replicated these findings. Carey et al. (2016) found an association between PRS scores of schizophrenia and cannabis use in a sample of 2573 adults (mean age 38.7 years). Verweij et al. (2017) found an association with initiation of cannabis, more regular use of cannabis, and more cannabis use over their lifetime in a sample of 6931 adults (mean age 43 years). In contrast, Sherva et al. (2016) did not find an association between schizophrenia genetic risk alleles and cannabis dependency among 6000 African-American and 8754 European participants (mean age was 39.2 years).

For smoking, a recent study showed an association between schizophrenia polygenic risk threshold $\left(p_{t}<0.005 ; p_{t}<0.05 ; p_{t}<0.5\right)$ and nicotine dependence and cigarettes smoked per day (Chen et al., 2016). However, the genetic variants most strongly associated with schizophrenia (i.e., threshold $p_{t}<5 \mathrm{e}-4$ and $p_{t}<5 \mathrm{e}-5$ ) were not associated with smoking. Carey et al. (2016) also found that schizophrenia PRS was associated with tobacco use compared to non-use. Also for other smoking phenotypes (e.g., age of onset, cigarettes per day) a genetic correlation with schizophrenia was reported (e.g., BulikSullivan et al., 2015; Hartz et al., 2018). Only one study examined the association between PRS and alcohol use and the results showed that elevated schizophrenia PRS were associated with severe alcohol dependence (Carey et al., 2016).

An explanation for contrasting findings could be sample ascertainment and phenotypic definitions (Walters and Owen, 2016). In addition, previous studies measured substance use retrospectively and the cross-sectional designs do not inform when such genetic risk is expressed and what the role of the potential onset of symptoms is (Power et al., 2014). Therefore, longitudinal studies on the relation between genetic risk for schizophrenia and patterns of increasing substance use during adolescence are needed. The focus on adolescence is important because the onset of substance use often starts during this age period and is often associated with substance use addiction (e.g., Chassin et al., 2000) and future health problems.

The present longitudinal study aimed to investigate whether genetic predisposition to schizophrenia, as reflected in schizophrenia PRS (at a chosen $p$-value threshold of $5 \mathrm{e}-8$ to 0.5 ), was associated with a pattern of increasing substance use (i.e., cannabis use, smoking, alcohol use) during adolescence (from ages $13-20$ years) in a general population sample. Based on previous research, we expected that adolescents with a genetic loading for schizophrenia would use substances more frequently and would have a stronger increase over time. A difference in substance use between age 13-16 and 16-20 was hypothesized since it was legal to smoke and drink at age 16 in the Netherlands until 2013. Moreover, cannabis use before the age of 16 is rare (van Dorsselaer et al., 2016). Considering the differences in schizophrenia risk between men and women (Aleman et al., 2003) as well as the different relation between substance use and psychotic symptoms in men and women (van Gastel et al., 2013) the relation between schizophrenia genes and substance use may be gender specific. To investigate this relation, we analyzed the interaction of PRS and gender in predicting patterns of increasing substance use. We expected that genetic predisposition to schizophrenia would be stronger associated with substance use in girls considering the stronger relationship between cannabis and psychoticlike experiences in women (van Gastel et al., 2013). Overall, the present longitudinal study can provide more insight into the shared genetic risk between schizophrenia and substance use.

\section{Methods}

\subsection{Procedure}

Data of the RADAR-Y (Research on Adolescent Development and Relationships Young cohort) study were used, which is an ongoing longitudinal Dutch community study in which adolescents have been followed from mean age 13 onwards. Adolescents were recruited from randomly selected secondary schools in the western and central parts of the Netherlands. In total, 230 (69\%) of the invited schools were willing to participate. Before the start of the study, adolescents and their parents received a complete description of the study and provided active written informed consent to participate $(N=497)$.

Between 2005 and 2012 (time T1-T7), trained research assistants first annually (T1-T6) and later biannually (T7) visited the adolescents in their homes to supervise the data collection and provide verbal instructions in addition to the written instructions that accompanied the questionnaires. At T5, buccal swabs were obtained, and DNA was extracted using the Chemagic saliva isolation kit on a Chemagen Module I workstation (Chemagen Biopolymer Technologie AG, Baesweiler, Germany). Overall, 372 adolescents agreed to provide genetic data. At each wave, adolescents received 30 euros for their participation. For the DNA extraction in combination with other experiments adolescents received an additional 50 euros. The study was approved by the Medical Ethical Committee of the Utrecht Medical Centre in the Netherlands.

\subsection{Participants}

At T1, 497 adolescents participated. Sample attrition was low across waves, with 384 adolescents (attrition of approximately 3.8\% every wave) still participating at T7. Adolescents' mean age at T1 was 13.00 years $(S D=0.44)$ and included $57 \%$ boys. All families were of ethnic Dutch. Most adolescents had middle or high socioeconomic status based on parents' job level (92.9\%; see also (Keijsers et al., 2012). We did not collect data on psychiatric diagnoses.

Of these 497 subjects, only the 372 adolescents who agreed to provide genetic data, are included in the current study. Attrition analysis showed that genotyped adolescents $(n=372)$ had a higher socioeconomic status compared to non-genotyped adolescents $(n=125)$ $(O R=3.61,95 \% C I=1.90-6.86, p<.001)$ and used less cannabis at $\mathrm{T} 1$ (OR $=0.15,95 \% C I=0.30-0.79, p=.03$ ). The results indicated no differences between genotyped and non-genotyped adolescents in age, gender, smoking T1, frequency of alcohol use T1, and binge drinking T1.

Pre-processing genotype data are included in Supplement 2. 


\subsection{Measures}

\subsubsection{Cannabis use}

At each with one question "In the past 12 months, how often have you used weed, marihuana or hashish?". Response categories ranged from 0 (no use) to 13 (40 times or more) (Monshouwer et al., 2006). Because of the skewed distribution, responses were dichotomized into 0 (never used in the past 12 months) and 1 (used at least once in the past 12 months).

\subsubsection{Smoking}

At each wave, adolescents indicated, using a valid and reliable measure which stage of smoking applied to them. Response categories ranged from 1 "I have never smoked, not even one puff" to 9 "I smoke at least once a day" (Kremers et al., 2001). Because of the skewed distribution, this variable was recoded into a new variable ranging from 1 to 5 ( 1 = never smoked; $2=$ tried smoking; $3=$ stopped smoking; $4=$ smokes occasionally but not every day; and $5=$ smokes daily; de Leeuw et al., 2010).

\subsubsection{Frequency of alcohol use and binge drinking}

At waves T1-T6, alcohol use was measured with two questions, one for frequency of alcohol use: "How often did you drink alcohol in the last 4 weeks?" and one for binge drinking: "How often did you drink more than 6 glasses of alcohol in the last 4 weeks?" (adapted version, based on Engels et al., 1999). Responses ranged from 1 (no alcohol use) to 5 (every day). Because of the skewed distribution, this was recoded into four categories for "alcohol in the last 4 weeks" $(0=$ no alcohol; $1=1-3$ day in the last 4 weeks; $2=1-2$ days per week; $3=$ more than 3 days per week) and 3 categories for "drinking more than six glasses alcohol" ( $0=$ no alcohol; $1=1-3$ day in the last 4 weeks; $2=$ at least 1-2 days per week). At T7, frequency of alcohol use and binge drinking was measured with different questions than T1-T6. Analyses for alcohol use were performed for $\mathrm{T} 1$ to $\mathrm{T} 6$ only.

\subsection{Statistical analysis}

To examine the pattern of increasing cannabis use, smoking, and alcohol use, Latent Growth Curve modelling as implemented in Mplus version 7.3 (Muthén and Muthén, 2010) was used to describe normative developmental patterns of behaviors (Willett and Sayer, 1994). Substance use pattern was represented by latent factors; an intercept (i.e., mean level of cannabis use, smoking or alcohol) and slope factor (i.e., mean change in cannabis use, smoking, or alcohol). Significant variance in the growth curve parameters (i.e., intercept and slope) indicates that individual growth patterns deviate from average. Specifically, we used a piecewise latent growth model (PLGC), which allows incorporation of separate growth profiles corresponding to different developmental stages (i.e., slopes) (Chou et al., 2004). We used this PLGC because we expected a difference in substance use before and after the age of 16 . It was legal until 2013 to smoke and drink at age 16 in the Netherlands. Therefore, the pattern of substance use was captured in two phases (i.e., two slopes): the first phase of substance use included age 13-16 (i.e., T1-T4) and the second phase of substance use includes ages 16-20 (i.e., T4-T7) for smoking and cannabis use and age 16-18 (T4-T6) for alcohol use, because alcohol use at age 20 was measured with different questions than previous measures (see also measures section).

Parameters in the models were estimated by applying maximum likelihood estimator with robust standard errors, or MLR, to correct for the non-normal distribution of the dependent variables. Additionally, to accommodate the categorical structure of the outcome variables, the CATEGORICAL option of Mplus was used (Muthén and Muthén, 2010). To deal with missing data (i.e., $11.6 \%$ over 7 waves), we used fullinformation maximum likelihood (FIML; Muthén and Muthén, 2010). For these models, Mplus did not provide fit indexes.

Associations between the PRS thresholds and the pattern of the curves of cannabis use, smoking and alcohol use were examined in separate hierarchical regression-type models for each threshold. In a first model, the association of gender and socio-economic status (SES) with the outcome variables was assessed. SES was included because of differences between genotyped and non-genotyped adolescents on SES. Furthermore, we expected that SES could be a confounder: the lower the SES, the more substance use is expected. In the second model PRS was added. In the third model, the interaction effect between PRS and gender was added. If an interaction was found, separate analyses for boys and girls were performed (see Supplement Table A). To show how much of the association between schizophrenia and substance use is due to shared genetic etiology, the variance explained (i.e., R-squared) by PRS will be presented of models that only included PRS. Bonferroni correction was used to show that an association between PRS and outcome variable was significant (i.e., p-value was $\leq .001$ based on 4 outcomes and 12 PRS thresholds).

\section{Results}

\subsection{Descriptive statistics}

During adolescence, substance use substantially increased (see Table 1). For cannabis use, most of the 372 adolescents were non-users

Table 1

Descriptive statistics (percentage) for cannabis use, smoking, frequency of alcohol use, and binge drinking during adolescence (age.13-20).

\begin{tabular}{|c|c|c|c|c|c|c|c|c|}
\hline Variable & Age 13 & Age 14 & Age 15 & Age 16 & Age 17 & Age 18 & Age 20 & Range \\
\hline Cannabis use & & & & & & & & $0-1$ \\
\hline No use in the last 12 months & 99.2 & 95.8 & 83.9 & 75.8 & 70.8 & 64.7 & 51.1 & \\
\hline Use in the last 12 months & 0.8 & 4.2 & 16.1 & 24.2 & 29.2 & 35.3 & 48.9 & \\
\hline Smoking & & & & & & & & $1-5$ \\
\hline Never smoked & 77.2 & 69.1 & 54.7 & 56.7 & 39.0 & 36.9 & 24.7 & \\
\hline Tried smoking & 18.2 & 20.5 & 23.5 & 24.5 & 23.8 & 20.3 & 23.5 & \\
\hline Stopped smoking & 0.8 & 3.4 & 3.4 & 3.7 & 3.7 & 5.6 & 5.9 & \\
\hline Smokes occasionally but not every day & 3.0 & 5.1 & 8.2 & 10.8 & 14.3 & 15.5 & 19.1 & \\
\hline Daily smoking & 0.8 & 2.0 & 10.2 & 14.2 & 19.2 & 21.7 & 26.9 & \\
\hline Frequency of alcohol use (last 4 weeks) & & & & & & & & $0-3$ \\
\hline No alcohol use & 82.5 & 68.2 & 49.6 & 24.1 & 14.5 & 12.8 & $--^{a}$ & \\
\hline $1-3$ days in the last 4 weeks & 15.9 & 27.8 & 40.6 & 47.7 & 35.0 & 30.4 & $-{ }^{\mathrm{a}}$ & \\
\hline 1-2 days per week & 0.0 & 4.0 & 8.6 & 23.3 & 42.8 & 41.5 & $-{ }^{\mathrm{a}}$ & \\
\hline More than 3 days a week & 1.1 & 0.0 & 1.2 & 4.9 & 7.8 & 15.3 & $-{ }^{\mathrm{a}}$ & \\
\hline Binge drinking (more than 6 glasses) & & & & & & & & $0-2$ \\
\hline No alcohol & 96.1 & 88.5 & 80.2 & 59.8 & 38.0 & 35.6 & $-{ }^{\mathrm{a}}$ & \\
\hline $1-3$ days in the last 4 weeks & 3.6 & 10.6 & 16.7 & 28.9 & 42.0 & 33.9 & $--^{a}$ & \\
\hline At least $1-2$ days per week & 0.3 & 0.9 & 3.2 & 11.3 & 20.0 & 30.5 & $-{ }^{\mathrm{a}}$ & \\
\hline
\end{tabular}

${ }^{\text {a }}$ At age 20, frequency of alcohol use and binge drinking were measured with another instrument. 
at baseline (T1; 99.2\%). This decreased to $51.1 \%$ at T7. For smoking, $77.2 \%$ of the adolescents were non-smoker at T1. However, daily smoking increased from $0.8 \%$ at $\mathrm{T} 1$ to $26.9 \%$ at T7. For frequency of alcohol use, at T1 $82.5 \%$ of the adolescents indicated that they did not use alcohol in the last 4 weeks, which decreased to $12.8 \%$ at T6. For binge drinking, at T1 $0.3 \%$ of the adolescents drank at least 1-2 days a week more than six glasses. This increased to $30.5 \%$ at $\mathrm{T} 6$.

Gender differences were found for cannabis use and alcohol use: boys used more than girls. For smoking no gender difference was found. More specifically, gender differences were found for: cannabis use in late adolescence T5-T7 (T5: $\mathrm{t}(344)=3.42, p=0.001 ; \mathrm{T} 6: \mathrm{t}$ $(344)=3.81, p<.001$; T7: $\mathrm{t}(310)=5.08, p<.001)$, frequency of alcohol use at T2, T4-T6, (T2: $\mathrm{t}(342)=2.20, p=.03 ; \mathrm{T} 4: \mathrm{t}(338)=3.75$, $p<.001 ; \mathrm{T} 5: \mathrm{t}(344)=4.58, p<.001 ; \mathrm{T} 6: \mathrm{t}(350)=5.92, p<.001)$ and binge drinking T4 - T6 (T4: $\mathrm{t}(336)=3.06, p=.002$; $\mathrm{T} 5: \mathrm{t}(343)=$ 5.67, $p<.001$; T6: $\mathrm{t}(349)=4.54, p<.001)$.

\subsection{Schizophrenia PRS associated with patterns of increasing substance use}

\subsubsection{Cannabis use}

No relation of gender and SES with initial levels of cannabis use or changes during adolescence was found. Positive associations between PRS and increases in cannabis use age 16-20 were found for two subsequent thresholds $p_{t}<5 \mathrm{e}-5$ and $p_{t}<5 \mathrm{e}-4$ (marginally significant $p_{t}<$ 5e-6) (Table 2a). However, for thresholds $p_{t}<5 \mathrm{e}-3$ to $p_{t}<0.5$ contrasting results were found: Higher schizophrenia PRS was associated with a lower increase in cannabis use age 16-20. Fig. 1 gives an example of the increase in cannabis use for adolescents with high versus low PRS (based on median split) of a significant threshold (all figures can be found in the Supplement to Fig. 1). Schizophrenia PRS explained between $4.5 \%-32.0 \%$ of the variance in cannabis use increase during late adolescence (the second slope). The model of the low thresholds that showed a relation with a lower increase in cannabis use explained $34.3 \%-34.9 \%$. of variances. Explained variances cannot be viewed as a measure of heritability nor represent the explained variance of the genetic contribution to this trait.

Marginally significant interactions between PRS and gender were found on intercept and slope of cannabis use age 16-20. However, no more than two out of 12 consecutive thresholds were marginally significant (intercept: $p_{t}<5 \mathrm{e}-8$ and $p_{t}<5 \mathrm{e}-7$ and slope $2: p_{t}<5 \mathrm{e}-5$ and $\left.p_{t}<5 \mathrm{e}-4\right)$. More specific, stratified analyses of cannabis use by gender (see Supplementary Table A) showed that higher schizophrenia PRS was associated with higher initial levels of cannabis use in girls (threshold: $p_{t}<5 \mathrm{e}-8, p_{t}<5 \mathrm{e}-7$ ). For changes in cannabis use age 16-20, we found for threshold $p_{t}<5 \mathrm{e}-6$ that boys with high schizophrenia PRS had a stronger increase in cannabis use over time. For thresholds $p_{t}<5 \mathrm{e}-5$ and $p_{t}<5 \mathrm{e}-4$, we found both boys and girls with high schizophrenia PRS had a higher increase in cannabis use over time. This increase was stronger among boys than girls. For the more lenient thresholds $\left(p_{t}<5 \mathrm{e}-3\right.$ to $\left.p_{t}<0.5\right)$, we found that for both boys and girls high schizophrenia PRS was associated with a lower increase in cannabis use age 16-20. Boys had a lower increase compared to girls.

\subsubsection{Smoking}

We found that gender was nominally associated with change in smoking frequency age $16-20(\beta=-0.42$, SE $=0.18, p=.02)$. Girls showed a lower increase in smoking age 16-20 compared to boys. No direct associations between PRS thresholds and initial smoking and changes in smoking over time were found. However, a marginally moderating effect of gender for different consecutive thresholds

\section{Table 2a}

Associations between schizophrenia polygenetic risk scores (p-value thresholds $\left.\left(\mathrm{p}_{\mathrm{t}}\right)\right)$ and initial (intercept) and changes ((slope 1: age 13-16) and slope 2: age 16-20) of cannabis use and smoking.

\begin{tabular}{|c|c|c|c|c|c|c|c|}
\hline & \multicolumn{4}{|c|}{ Polygenic risk score thresholds Cannabis use } & \multicolumn{3}{|l|}{ Smoking } \\
\hline & & $\begin{array}{l}\text { Intercept } \\
\beta(S E)\end{array}$ & $\begin{array}{l}\text { Slope } 1 \\
\beta(S E)\end{array}$ & $\begin{array}{l}\text { Slope } 2 \\
\beta \text { (SE) }\end{array}$ & $\begin{array}{l}\text { Intercept } \\
\beta(S E)\end{array}$ & $\begin{array}{l}\text { Slope } 1 \\
\beta(S E)\end{array}$ & $\begin{array}{l}\text { Slope } 2 \\
\beta \text { (SE) }\end{array}$ \\
\hline Step 1 & Gender $^{\mathrm{a}}$ & $-0.60(0.52)$ & $-0.09(0.27)$ & $-0.37(0.22)$ & $-0.22(0.15)$ & $0.28(0.16)$ & $-0.42(0.18)^{*}$ \\
\hline \multirow[t]{13}{*}{ Step 2} & SES $^{\mathrm{b}}$ & $0.26(0.77)$ & $-0.27(0.41)$ & $-0.02(0.44)$ & $0.42(0.25)$ & $-0.36(0.25)$ & $0.48(0.36)$ \\
\hline & $p_{t}<5 \mathrm{e}-8^{\mathrm{c}}$ & $0.25(0.18)$ & $-0.15(0.13)$ & $0.11(0.10)$ & $0.10(0.08)$ & $0.01(0.08)$ & $0.003(0.09)$ \\
\hline & $p_{t}<5 \mathrm{e}-7^{\mathrm{c}}$ & $0.18(0.18)$ & $-0.08(0.13)$ & $0.001(0.11)$ & $0.04(0.07)$ & $0.08(0.08)$ & $-0.06(0.09)$ \\
\hline & $p_{t}<5 \mathrm{e}-6^{\mathrm{c}}$ & $0.02(0.18)$ & $-0.08(0.12)$ & $0.24(0.09)^{* *}$ & $-0.02(0.08)$ & $0.07(0.07)$ & $-0.04(0.10)$ \\
\hline & $p_{t}<5 \mathrm{e}-5^{\mathrm{c}}$ & $-0.01(0.16)$ & $-0.10(0.11)$ & $0.54(0.08)^{* * * *}$ & $0.02(0.08)$ & $0.03(0.08)$ & $-0.05(0.14)$ \\
\hline & $p_{t}<5 \mathrm{e}-4^{\mathrm{c}}$ & $-0.01(0.17)$ & $-0.10(0.11)$ & $0.57(0.08)^{* * *}$ & $0.02(0.08)$ & $0.02(0.08)$ & $-0.06(0.15)$ \\
\hline & $p_{t}<0.005^{c}$ & $-0.03(0.17)$ & $0.13(0.11)$ & $-0.59(0.08)^{* * *}$ & $0.03(0.08)$ & $-0.01(0.08)$ & $0.06(0.15)$ \\
\hline & $p_{t}<0.05^{\mathrm{c}}$ & $-0.01(0.17)$ & $0.12(0.11)$ & $-0.60(0.08)^{* * *}$ & $-0.03(0.08)$ & $-0.01(0.08)$ & $0.06(0.15)$ \\
\hline & $p_{t}<0.1^{\mathrm{c}}$ & $-0.004(0.17)$ & $0.12(0.11)$ & $-0.59(0.07)^{* * *}$ & $-0.03(0.08)$ & $-0.01(0.08)$ & $0.05(0.15)$ \\
\hline & $p_{t}<0.2^{\mathrm{c}}$ & $-0.003(0.17)$ & $0.12(0.11)$ & $-0.59(0.07)^{* * *}$ & $-0.03(0.08)$ & $-0.01(0.08)$ & $0.05(0.16)$ \\
\hline & $p_{t}<0.3^{\mathrm{c}}$ & $-0.003(0.17)$ & $0.11(0.11)$ & $-0.59(0.08)^{* * *}$ & $-0.03(0.08)$ & $-0.01(0.08)$ & $0.06(0.16)$ \\
\hline & $p_{t}<0.4^{\mathrm{c}}$ & $-0.002(0.17)$ & $0.11(0.11)$ & $-0.59(0.07)^{* * *}$ & $-0.03(0.08)$ & $-0.01(0.08)$ & $0.06(0.16)$ \\
\hline & $p_{t}<0.5^{\mathrm{c}}$ & $-0.002(0.17)$ & $0.11(0.11)$ & $-0.59(0.07)^{* * *}$ & $-0.03(0.08)$ & $-0.01(0.08)$ & $0.06(0.16)$ \\
\hline \multirow[t]{12}{*}{ Step 3} & $p_{t}<5 \mathrm{e}-8^{\mathrm{c}} *$ gender & $0.55(0.27)^{*}$ & $-0.20(0.20)$ & $-0.11(0.14)$ & $0.01(0.11)$ & $0.12(0.10)$ & $-0.12(0.13)$ \\
\hline & $p_{t}<5 \mathrm{e}-7^{\mathrm{c}}$ *gender & $0.50(0.19)^{* *}$ & $-0.14(0.18)$ & $-0.16(0.15)$ & $0.10(0.10)$ & $0.05(0.12)$ & $-0.17(0.13)$ \\
\hline & $p_{t}<5 \mathrm{e}-6^{\mathrm{c}} *$ gender & $0.32(0.26)$ & $-0.15(0.17)$ & $-0.15(0.12)$ & $-0.01(0.10)$ & $0.06(0.10)$ & $-0.07(0.14)$ \\
\hline & $p_{t}<5 \mathrm{e}-5^{\mathrm{c}} *$ gender & $0.09(0.31)$ & $-0.02(0.19)$ & $-0.21(0.10)^{*}$ & $-0.20(0.10)^{*}$ & $0.06(0.10)$ & $0.14(0.16)$ \\
\hline & $p_{t}<5 \mathrm{e}-4^{\mathrm{c}} *$ gender & $-0.03(0.26)$ & $0.03(0.16)$ & $-0.23(0.10)^{*}$ & $-0.24(0.10)^{* *}$ & $0.03(0.11)$ & $0.24(0.18)$ \\
\hline & $p_{t}<0.005^{\mathrm{c}}$ *gender & $0.12(0.26)$ & $-0.07(0.15)$ & $0.18(0.10)$ & $0.29(0.10)^{* *}$ & $-0.05(0.11)$ & $-0.27(0.18)$ \\
\hline & $p_{t}<0.05^{\mathrm{c}} *$ gender & $0.08(0.26)$ & $-0.04(0.15)$ & $0.18(0.10)$ & $0.28(0.10)^{* *}$ & $-0.05(0.11)$ & $-0.28(0.18)$ \\
\hline & $p_{t}<0.1^{c} *$ gender & $0.09(0.27)$ & $-0.04(0.15)$ & $0.18(0.10)$ & $0.28(0.10)^{* *}$ & $-0.05(0.11)$ & $-0.28(0.18)$ \\
\hline & $p_{t}<0.2^{\mathrm{c}} *$ gender & $0.09(0.44)$ & $-0.04(0.15)$ & $0.19(0.13)$ & $0.28(0.10)^{* *}$ & $-0.04(0.11)$ & $-0.28(0.18)$ \\
\hline & $p_{t}<0.3^{\mathrm{c}}$ *gender & $0.08(0.25)$ & $-0.04(0.15)$ & $0.19(0.10)$ & $0.28(0.10)^{* *}$ & $-0.04(0.11)$ & $-0.28(0.18)$ \\
\hline & $p_{t}<0.4^{\mathrm{c}} *$ gender & $0.08(0.28)$ & $-0.04(0.15)$ & $0.19(0.10)$ & $0.28(0.10)^{* *}$ & $-0.04(0.11)$ & $-0.28(0.18)$ \\
\hline & $p_{t}<0.5^{\mathrm{c}} *$ gender & $0.08(0.28)$ & $-0.04(0.15)$ & $0.19(0.10)$ & $0.28(0.10)^{* *}$ & $-0.04(0.11)$ & $-0.28(0.18)$ \\
\hline
\end{tabular}

a $0=$ boys and $1=$ girl.

b $0=$ middle/high SES (Socio-Economic Status) $1=$ low SES; $\beta=$ Beta; $S E=$ Standard error; positive association $=$ strong increase; negative association $=$ lower increase; * $p<.05 ; * * p<.01, * * * p<.001$.

c 5 e-8 (nr SNPs = 189); 5e-7 (nr SNPs = 335); 5e-6 (nr SNPs = 695); 5e-5 (nr SNPs = 1696); 5e-4 (nr SNPs = 4907); 0.005 (nr SNPs = 17,973); 0.05 (nr SNPs = 74,935); 0.1 (nr SNPs = 117,057); $0.2(\mathrm{nr}$ SNPs = 181,385); 0.3 (nr SNPs = 233,942); 0.4 (nr SNPs = 279,087); 0.5 (nr SNPs = 318,774). 
(a)

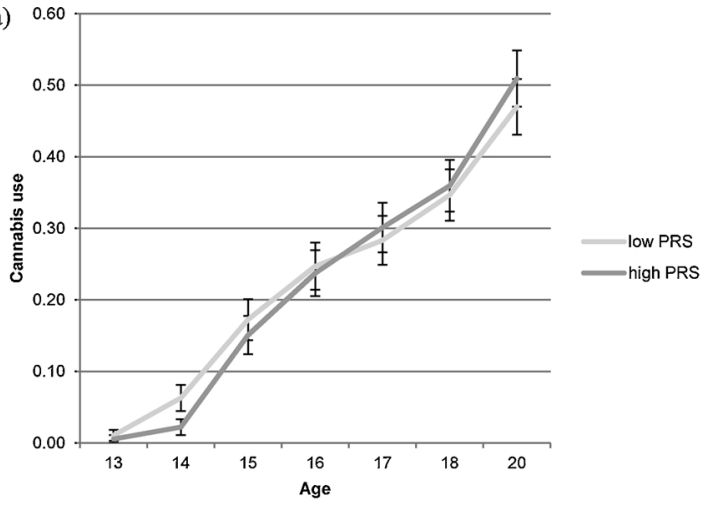

(b)

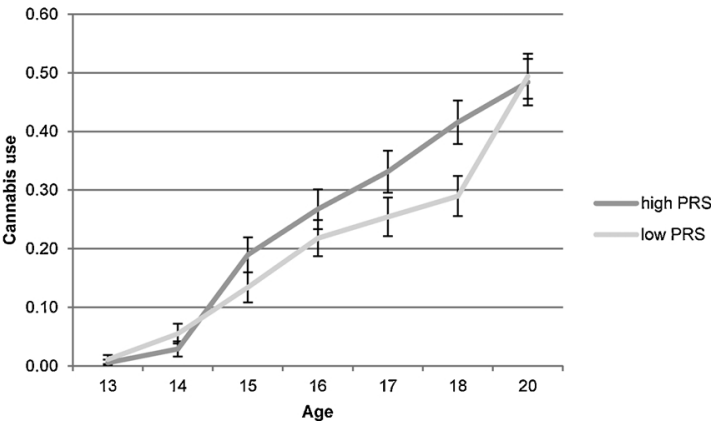

Fig. 1. Example of significant thresholds of Polygenic Risk Scores (PRS) of schizophrenia (a) threshold $p_{t}<5 \mathrm{e}-5$ with stronger increase of cannabis use age 16-20 and (b) threshold $p_{t}<0.3$ with a lower increase for cannabis age 16-20.

Note. Mean differences in cannabis use over time are based on median split (low versus high polygenic risk score (PRS)). Y-axis: cannabis was measured on a 0-1 scale (never used in the past 12 months versus used at least once in the past 12 months).

( $p_{t}<5 \mathrm{e}-5$ to $p_{t}<0.5$ ) on the initial levels of smoking was found. Stratified analyses for gender (see Supplementary Table A) showed contrasting results for boys and girls. Boys with high schizophrenia PRS had marginally lower levels of smoking and girls with high schizophrenia PRS had marginally higher levels of smoking (see Supplementary Table A). For smoking, the explained variance for schizophrenia PRS was between $0.9 \%-4.1 \%$ for boys and $0.1 \%-3.8 \%$ for girls.

\subsubsection{Frequency of alcohol use}

For alcohol use frequency in the last 4 weeks, we found that girls compared to boys had a marginally lower increase in alcohol age 16-20 $(\beta=-.64, \mathrm{SE}=0.22, p<.01)$. Adolescents with lower SES had marginally higher levels of alcohol use in the last 4 weeks at age 13 ( $\beta$ $=0.71, \mathrm{SE}=0.26, p<.01$ ), but a smaller increase age $16-20 \mathrm{com}-$ pared to adolescents with middle to high SES $(\beta=-0.76, \mathrm{SE}=0.35$, $p<.05)$. Several consecutive schizophrenia PRS thresholds were marginal significantly associated with a lower increase in alcohol use age 13-16 (see Table 2b). No interaction effects between PRS thresholds and gender were found. For frequency of alcohol use age 13-16, schizophrenia PRS explained $2.5 \%-4.6 \%$ of the variance.

\subsubsection{Binge drinking}

Binge drinking had a marginal significant lower increase in prevalence age $16-20$ in girls compared to boys $(\beta=-.46$, $\mathrm{SE}=0.18$, $p<.01$ ). Besides this, the association between SES and initial levels of alcohol use (more than six drinks) was also marginally significant $(\beta=$ $0.77, \mathrm{SE}=0.34, p<0.05$ ). Adolescents with lower SES had higher levels of binge drinking compared to adolescents with middle to high SES. We found that high schizophrenia PRS thresholds were marginally associated with attenuated increases of binge drinking age 16-20 (threshold: $p_{t}<0.05$ to $p_{t}<0.5$ ). The results of binge drinking T1-T6 should be interpreted with some caution, because alcohol use measured at T7 (measured with other instruments) showed no mean difference between binge drinking and low and high schizophrenia vulnerability (based on median split) $\mathrm{t}(326)=1.36, p=.18)$. No moderating effects of gender were found. For binge drinking, schizophrenia PRS explained between $4.0 \%-4.9 \%$ of the variance age $16-20$.

\section{Discussion}

In the present study, we examined whether increased genetic risk for schizophrenia was associated with patterns of substance use (i.e., cannabis use, smoking, and alcohol use) from early to late adolescence in a general population sample. The results showed that schizophrenia PRS is associated with diverging patterns of cannabis use across adolescence. High schizophrenia vulnerability was related to a stronger increase in cannabis use after age 16, whereas more lenient PRS thresholds after age 16 showed the reverse. For smoking, and alcohol use no clear evidence of a relation with schizophrenia PRS was found.

The relation between higher schizophrenia PRS (i.e., thresholds $p_{t}<5 \mathrm{e}-5$ and $p_{t}<5 \mathrm{e}-4$ ) and cannabis use is in line with previous crosssectional studies that reported that individuals with higher genetic vulnerability for schizophrenia were more likely to commence cannabis use and used in greater amounts (i.e., Carey et al., 2016; Power et al., 2014; Verweij et al., 2017). We extend these previous cross-sectional findings by showing that PRS that are based on strongly associated genetic variants of schizophrenia (i.e., thresholds $p_{t}<5 \mathrm{e}-5$ and $\left.p_{t}<5 \mathrm{e}-4\right)$ increase cannabis use in late adolescence whereas schizophrenia PRS based on a more lenient threshold (i.e., thresholds $p_{t}<5 \mathrm{e}$ 3 to $p_{t}<0.5$ ) are related to decreased propensity to use cannabis in early adolescence. This latter finding raises the question whether the low threshold PRS constitute more general psychiatric vulnerability and are perhaps associated with a decreased tendency to engage in the experimental behavior, and whether the high thresholds PRS reflect more defined schizophrenia risk. However, more research on this methodological explanation is needed, and limited power of this study may also be at play. Considering the large sample size of the discovery GWAS into schizophrenia, the PRS is generally deemed reliable. However, the construct of the different threshold is not entirely clear. Whereas from a statistical perspective a dose relationship (more stringent PRS thresholds show increased strength of associations) reflect reliable relations, from a more clinical perspective we know that many of the psychiatric traits have a shared phenomenology, and genetic background (Boks et al., 2007; Derks et al., 2012) and therefore genetic risk to schizophrenia may in part be driven to general mental illness susceptibility genes. The longitudinal relationship between schizophrenia PRS and cannabis use may point to a joint genetic background of cannabis use and schizophrenia but also leaves room for speculation about cannabis use as part of a causal pathway towards schizophrenia (Vaucher et al., 2017).

Although the longitudinal design is a strength, limitations remain. First, adolescents reported on their substance use using one single item per substance. This might have led to measurement errors, and therefore objective measures (e.g., laboratory testing of blood, urine, or saliva) are preferred (e.g., Buchan et al., 2002), although previous research has shown that self-report data on substance use are generally reliable when confidentiality is assured (e.g., Basurto et al., 2009; Del Boca and Noll, 2000; Dolcini et al., 2003). Second, binge drinking (i.e., in the current study defined as drinking more than six glasses of alcohol) was not normed by gender. In future studies, different questions for girls and boys would pose an improvement. Third, smoking was used as a categorical variable, however, the order of categories in the smoking measure is debatable (i.e., never smoked, tried smoking, stopped smoking, smokes occasionally, smokes daily; de Leeuw et al., 2010). Fourth, even though we used a longitudinal design, this study 
Table 2b

Associations between schizophrenia polygenetic risk scores ( $p$-value thresholds $\left(\mathrm{p}_{\mathrm{t}}\right)$ ) and initial (intercept) and changes ((slope 1: age 13-16) and slope 2: age 16-20) of frequency of alcohol use and binge drinking.

\begin{tabular}{|c|c|c|c|c|c|c|c|}
\hline & \multicolumn{4}{|c|}{ Polygenic risk score thresholds Frequency of alcohol use } & \multicolumn{3}{|l|}{ Binge drinking } \\
\hline & & $\begin{array}{l}\text { Intercept } \\
\beta(S E)\end{array}$ & $\begin{array}{l}\text { Slope } 1 \\
\beta(S E)\end{array}$ & $\begin{array}{l}\text { Slope } 2 \\
\beta(S E)\end{array}$ & $\begin{array}{l}\text { Intercept } \\
\beta(S E)\end{array}$ & $\begin{array}{l}\text { Slope } 1 \\
\beta(S E)\end{array}$ & $\begin{array}{l}\text { Slope } 2 \\
\beta \text { (SE) }\end{array}$ \\
\hline \multirow{14}{*}{$\begin{array}{l}\text { Step } 1 \\
\text { Step } 2\end{array}$} & Gender $^{\mathrm{a}}$ & $-0.22(0.16)$ & $-0.13(0.19)$ & $-0.64(0.22)^{* *}$ & $0.24(0.22)$ & $-0.45(0.25)$ & $-0.46(0.18)^{* *}$ \\
\hline & $\mathrm{SES}^{\mathrm{b}}$ & $0.71(0.26)^{* *}$ & $-0.76(0.35)^{*}$ & $-0.38(0.13)$ & $0.77(0.34)^{*}$ & $-0.74(0.41)$ & $-0.11(0.39)$ \\
\hline & $p_{t}<5 \mathrm{e}-8^{\mathrm{c}}$ & $-0.006(0.08)$ & $0.04(0.08)$ & $0.04(0.11)$ & $0.32(0.50)$ & $0.11(1.85)$ & $-1.49(2.58)$ \\
\hline & $p_{t}<5 \mathrm{e}-7^{c}$ & $0.02(0.08)$ & $-0.04(0.08)$ & $-0.003(0.11)$ & $0.26(0.42)$ & $-0.79(1.62)$ & $-1.05(2.19)$ \\
\hline & $p_{t}<5 \mathrm{e}-6^{\mathrm{c}}$ & $0.06(0.08)$ & $-0.10(0.09)$ & $0.08(0.12)$ & $0.06(0.10)$ & $-0.05(0.11)$ & $-0.04(0.10)$ \\
\hline & $p_{t}<5 \mathrm{e}-5^{c}$ & $0.11(0.08)$ & $-0.19(0.09) *$ & $0.02(0.11)$ & $0.01(0.11)$ & $-0.03(0.12)$ & $-0.10(0.09)$ \\
\hline & $p_{t}<5 \mathrm{e}-4^{\mathrm{c}}$ & $0.12(0.08)$ & $-0.22(0.09) *$ & $0.02(0.11)$ & $0.01(0.13)$ & $-0.06(0.14)$ & $-0.11(0.09)$ \\
\hline & $p_{t}<0.005^{\mathrm{c}}$ & $0.10(0.08)$ & $-0.16(0.09)$ & $-0.01(0.10)$ & $-0.06(0.13)$ & $0.05(0.15)$ & $-0.16(0.09)$ \\
\hline & $p_{t}<0.05^{c}$ & $0.08(0.07)$ & $-0.16(0.08)^{*}$ & $-0.12(0.10)$ & $-0.05(0.13)$ & $0.02(0.16)$ & $-0.19(0.09)^{*}$ \\
\hline & $p_{t}<0.1^{c}$ & $0.08(0.07)$ & $-0.16(0.08)^{*}$ & $-0.16(0.11)$ & $-0.05(0.13)$ & $0.02(0.16)$ & $-0.22(0.09)^{*}$ \\
\hline & $p_{t}<0.2^{\mathrm{c}}$ & $0.08(0.07)$ & $-0.17(0.08) *$ & $-0.12(0.11)$ & $-0.01(0.12)$ & $-0.02(0.15)$ & $-0.20(0.09)^{*}$ \\
\hline & $p_{t}<0.3^{\mathrm{c}}$ & $0.07(0.07)$ & $-0.17(0.08)^{*}$ & $-0.11(0.11)$ & $-0.02(0.12)$ & $-0.03(0.15)$ & $-0.20(0.10)^{*}$ \\
\hline & $p_{t}<0.4^{\mathrm{c}}$ & $0.07(0.07)$ & $-0.17(0.08) *$ & $-0.11(0.11)$ & $-0.02(0.12)$ & $-0.02(0.15)$ & $-0.19(0.10) *$ \\
\hline & $p_{t}<0.5^{\mathrm{c}}$ & $0.06(0.07)$ & $-0.15(0.08)$ & $-0.12(0.11)$ & $-0.03(0.12)$ & $-0.01(0.15)$ & $-0.20(0.10)^{*}$ \\
\hline \multirow[t]{12}{*}{ Step 3} & $p_{t}<5 \mathrm{e}-8^{\mathrm{c}} *$ gender & $0.20(0.11)$ & $-0.14(0.11)$ & $-0.14(0.16)$ & $0.18(0.14)$ & $-0.08(0.15)$ & $-0.12(0.13)$ \\
\hline & $p_{t}<5 \mathrm{e}-7^{\mathrm{c}} *$ gender & $0.20(0.11)$ & $-0.08(0.12)$ & $-0.14(0.17)$ & $0.10(0.14)$ & $0.04(0.16)$ & $-0.14(0.14)$ \\
\hline & $p_{t}<5 \mathrm{e}-6^{\mathrm{c}} *$ gender & $0.18(0.11)$ & $-0.10(0.12)$ & $-0.10(0.17)$ & $0.22(0.14)$ & $-0.10(0.15)$ & $-0.18(0.13)$ \\
\hline & $p_{t}<5 \mathrm{e}-5^{\mathrm{c}} *$ gender & $0.14(0.11)$ & $-0.04(0.13)$ & $-0.06(0.16)$ & $0.23(0.15)$ & $-0.04(0.16)$ & $-0.22(0.13)$ \\
\hline & $p_{t}<5 \mathrm{e}-4^{\mathrm{c}} *$ gender & $0.03(0.11)$ & $0.03(0.12)$ & $-0.06(0.15)$ & $0.15(0.16)$ & $-0.01(0.17)$ & $-0.21(0.12)$ \\
\hline & $p_{t}<0.005^{\mathrm{c}}$ *gender & $-0.05(0.11)$ & $0.07(0.12)$ & $-0.07(0.14)$ & $0.11(0.16)$ & $-0.02(0.19)$ & $-0.20(0.12)$ \\
\hline & $p_{t}<0.05^{\mathrm{c}} *$ gender & $-0.08(0.11)$ & $0.08(0.12)$ & $-0.03(0.15)$ & $0.13(0.17)$ & $-0.04(0.21)$ & $-0.23(0.14)$ \\
\hline & $p_{t}<0.1^{\mathrm{c}}$ *gender & $-0.10(0.10)$ & $0.10(0.12)$ & $-0.06(0.16)$ & $0.09(0.16)$ & $-0.01(0.20)$ & $-0.24(0.14)$ \\
\hline & $p_{t}<0.2^{\mathrm{c}} *$ gender & $-0.04(0.11)$ & $0.06(0.12)$ & $-0.06(0.16)$ & $0.12(0.16)$ & $-0.04(0.20)$ & $-0.20(0.15)$ \\
\hline & $p_{t}<0.3^{\mathrm{c}} *$ gender & $-0.04(0.11)$ & $0.05(0.12)$ & $-0.05(0.16)$ & $0.13(0.17)$ & $-0.08(0.21)$ & $-0.17(0.15)$ \\
\hline & $p_{t}<0.4^{\mathrm{c}}$ * gender & $-0.05(0.11)$ & $0.06(0.12)$ & $-0.05(0.16)$ & $0.12(0.16)$ & $-0.09(0.21)$ & $-0.17(0.15)$ \\
\hline & $p_{t}<0.5^{\mathrm{c}}$ *gender & $-0.06(0.11)$ & $0.06(0.12)$ & $-0.06(0.16)$ & $0.11(0.16)$ & $-0.08(0.20)$ & $-0.16(0.15)$ \\
\hline
\end{tabular}

a $0=$ boys and $1=$ girls.

b $0=$ middle/high SES (Socio-Economic Status) $1=$ low SES; $\beta=$ Beta; $S E=$ Standard error; positive association = strong increase; negative association = lower increase; ${ }^{*} p<.05 ; * * p<.01, * * * p<.001$.

c 5e-8 (nr SNPs = 189); 5e-7 (nr SNPs = 335); 5e-6 (nr SNPs = 695); $5 \mathrm{e}-5$ (nr SNPs = 1696); 5e-4 (nr SNPs = 4907); 0.005 (nr SNPs = 17,973); 0.05 (nr SNPs = 74,935); 0.1 (nr SNPs = 117,057); $0.2(\mathrm{nr}$ SNPs = 181,385); $0.3(\mathrm{nr}$ SNPs = 233,942); $0.4(\mathrm{nr}$ SNPs = 279,087); $0.5(\mathrm{nr}$ SNPs $=318,774)$.

had a relatively small sample size leading to limited power and limited generalizability to the larger population. Generalizability was limited further by only including ethnic Dutch adolescents in the current study.

Fifth, not all the thresholds showed significant relations. Although in many cases subsequent PRS thresholds did show significant results, to date the meaning of PRS based on low association alleles (thresholds $0.05-0.1$ ) and ways to deal with multiple testing remain subject to debate (Dudbridge, 2013). Moreover, limiting the power of the current study may also explain inconsistencies in the relations of subsequent PRS thresholds.

Sixth, future research could focus on the interaction between PRS and environmental factors (i.e., gene-environment interactions), like the influence of peers on substance use (e.g., Leung et al., 2014; SimonsMorton and Farhat, 2010). Finally, because of relatively small sample size and low incidence of substance use, this study may have limited power to find significant associations. More specifically, the power of PRS studies is determined by a combination of the strength of the discovery sample (from which the PRS scores are calculated) and characteristics of the studied sample. The fact that we do find relations testifies of the strong discovery as well as the strong relations with cannabis use, as also reflected in other previous studies (Power et al., 2014; Carey et al., 2016; Verweij et al., 2017).

\subsection{Conclusion}

Overall, the present study shows that genetic vulnerability to schizophrenia is related to patterns of cannabis use during adolescence. Further study is warranted to investigate whether this relation is the behavioral expression of genetic schizophrenia risk, or whether pervasive mental health characteristics or social influences lead to distinct substance use patterns.

\section{Role of funding source}

This work was supported by a Dynamics of Youth grant from the University Utrecht, the Netherlands. Data from the Research on Adolescent Development and Relationships (RADAR) study were used. RADAR has been financially supported by main grants from the Netherlands Organisation for Scientific Research (GB-MAGW 480-03005, GB-MAGW 480-08-006), the Stichting Achmea Slachtoffer en Samenleving (SASS), a grant from the Netherlands Organisation for Scientific Research to the Consortium Individual Development (CID; 024.001.003), and various other grants from the Netherlands Organisation for Scientific Research, the VU University Amsterdam, and Utrecht University. The funding sources had no further role in study design, the collection, analysis, and interpretation of data, the writing of the report, or in the decision to submit the paper for publication.

\section{Contributors}

$\mathrm{SB}, \mathrm{CV}, \mathrm{PvL}, \mathrm{WM}$, and $\mathrm{MB}$ contributed to study conception and design. SB, PvL, WM, and SN were responsible for acquisition of data. $\mathrm{MH}, \mathrm{SN}, \mathrm{KvE}$, and $\mathrm{JJH}$ performed analysis and interpretation of data. $\mathrm{MH}$ and MPB drafted the manuscript. SB, CV, PvL, WM, and MB aided in critical revision of the manuscript. All authors have read and approved the final manuscript.

\section{Conflict of interest}

No conflict declared. 


\section{Compliance with ethical standards}

All procedures performed in studies involving human participants were in accordance with the ethical standards of the institutional and/ or national research committee and with the 1964 Helsinki declaration and its later amendments or comparable ethical standards. Informed consent was obtained from all individual participants included in the study. Additional informed consent was obtained from all individual participants for whom identifying information is included in this article.

\section{Appendix A. Supplementary data}

Supplementary material related to this article can be found, in the online version, at doi:https://doi.org/10.1016/j.drugalcdep.2018.05. 024.

\section{References}

Aleman, A., Kahn, R.S., Selten, J.P., 2003. Sex differences in the risk of schizophrenia: evidence from meta-analysis. Arch. Gen. Psychiatry 60, 565-571.

Arseneault, L., Cannon, M., Poulton, R., Murray, R., Caspi, A., Moffitt, T.E., 2002. Cannabis use in adolescence and risk for adult psychosis: longitudinal prospective study. BMJ 325, 1212-1213.

Basurto, F.Z., Montes, J.M.G., Cubos, P.F., Santed, F.S., Ríos, F.L., Moreno, A.M., 2009. Validity of the self-report on drug use by university students: correspondence between self-reported use and use detected in urine. Psicothema 21, 213-219.

Boks, M.P., Leask, S., Vermunt, J.K., Kahn, R.S., 2007. The structure of psychosis revisited: the role of mood symptoms. Schizophr. Res. 93, 178-185.

Buchan, B.J., Dennis, M.L., Tims, F.M., Diamond, G.S., 2002. Cannabis use: consistency and validity of self-report, on-site urine testing and laboratory testing. Addiction 97, 98-108.

Bulik-Sullivan, B., Finucane, H.K., Anttila, V., Gusev, A., Day, F.R., Loh, ReproGen Consortium, Psychiatric Genomics Consortium, Genetic Consortium for Anorexia Nervosa of the Welcome Trust Case Control Consortium 3, Duncan, L., Perry, J.R.B., Patterson, N., Robinson, E.B., Daly, M.J., Price, A.L., Neale, B.M., 2015. An atlas of genetic correlations across human diseases and traits. Nat. Genet. 47, 1236-1241.

Carey, C.E., Agrawal, A., Bucholz, K.K., Hartz, S.M., Lynskey, M.T., Nelson, E.C., Bierut, L.J., Bogdan, R., 2016. Associations between polygenic risk for psychiatric disorders and substance involvement. Front. Genet. 7, 149.

Chassin, L., Presson, C.C., Pitts, S.C., Sherman, S.J., 2000. The natural history of cigarette smoking from adolescence to adulthood in a midwestern community sample: multiple trajectories and their psychosocial correlates. Health Psychol. 19, 223-231.

Chen, J., Bacanu, S.A., Yu, H., Zhao, Z., Jia, P., Kendler, K.S., Kranzier, H.R., Gelernter, J., Farrer, L., Minica, C., Pool, R., Milaneschi, Y., Boomsma, D., Pennix, B.W., Tyndale, R.F., Ware, J.J., Vink, J.M., Kaprio, J., Munafo, M., Chen, X., Cotinine meta-analysis group; FTND Meta-Analysis Group, 2016. Genetic relationship between schizophrenia and nicotine dependence. Sci. Rep. 6, 25671.

Chou, C.P., Yang, D., Pentz, M.A., Hser, Y.I., 2004. Piecewise growth curve modeling approach for longitudinal prevention study. Comput. Stat. Data Anal. 46, 213-225.

de Leeuw, R., Scholte, R., Vermulst, A., Engels, R., 2010. The relation between smokingspecific parenting and smoking trajectories of adolescents: how are changes in parenting related to changes in smoking? Psychol. Health 25, 999-1021.

de Leon, J., Diaz, F.J., 2005. A meta-analysis of worldwide studies demonstrates an association between schizophrenia and tobacco smoking behaviors. Schizophr. Res. 76, 135-157.

de Looze, M., van Dorsselaer, S., de Roos, S., Verdurmen, J., Stevens, G., Gommans, R., van Bon-Martens, M., ter Bogt, T., Volleberg, W., 2014. Gezondheid, Welzijn En Opvoeding Van Jongeren in Nederland [Health, Well-Being, and Parenting of Youth in the Netherlands]. Utrecht University.

Del Boca, F.K., Noll, J.A., 2000. Truth or consequences: the validity of self-report data in health services research on addictions. Addiction 95, S347-360.

Derks, E.M., Allardyce, J., Boks, M.P., Vermunt, J.K., Hijman, R., Ophoff, R.A., GROUP, 2012. Kraepelin was right: a latent class analysis of symptom dimensions in patients and controls. Schizophr. Bull. 38, 495-505.

Dolcini, M.M., Adler, N.E., Lee, P., Bauman, K.E., 2003. An assessment of the validity of adolescent self-reported smoking using three biological indicators. Nicotine Tob. Res. 5, 473-483.

Dudbridge, F., 2013. Power and predictive accuracy of polygenic risk scores. PLoS Genet. 9, e1003348.

Engels, R.C., Knibbe, R.A., Drop, M.J., 1999. Predictability of smoking in adolescence: between optimism and pessimism. Addiction 94, 115-124.

Gage, S.H., Munafo, M.R., 2015. Rethinking the association between smoking and schizophrenia. Lancet Psychiatry 2, 118-119.

Goldman, D., Oroszi, G., Ducci, F., 2005. The genetics of addictions: uncovering the genes. Nat. Rev. Genet. 6, 521-532.

Hartz, S.M., Horton, A.C., Hancock, D.B., Baker, T.B., Caporaso, N.E., Chen, L.S. Hokanson, J.E., Lutz, S.M., Marazita, M.L., McNeill, D.W., Pato, C.N., Pato, M.T., Johnson, E.O., Beirut, L.J., 2018. Genetic correlation between smoking behaviors and schizophrenia. Schizophr. Res. https://doi.org/10.1016/j.schres.2017.02.022.
Hibell, B., Guttormsson, U., Ahlström, S., Balakireva, O., Bjarnason, T., Kokkevi, A., Kraus, L., 2012. The 2011 ESPAD Report: Substance Use Among Students in 36 European Countries: Swedish Council for Information on Alcohol and Other Drugs Stockholm.

Ho, M.K., Tyndale, R.F., 2007. Overview of the pharmacogenomics of cigarette smoking. Pharmacogen. J. 7, 81-98.

Keijsers, L., Branje, S., Hawk, S.T., Schwartz, S.J., Frijns, T., Koot, H.M., van Lier, P., Meeus, W., 2012. Forbidden friends as forbidden fruit: parental supervision of friendships, contact with deviant peers, and adolescent delinquency. Child Dev. 83, 651-666.

Kendler, K.S., Lonn, S.L., Sundquist, J., Sundquist, K., 2015. Smoking and schizophrenia in population cohorts of Swedish women and men: a prospective co-relative control study. Am. J. Psychiatry 172, 1092-1100.

Kessler, R.C., McGonagle, K.A., Zhao, S., Nelson, C.B., Hughes, M., Eshleman, S., Wittchen, H.U., Kendler, K.S., 1994. Lifetime and 12-month prevalence of DSM-III-R psychiatric disorders in the United States. Results from the National Comorbidity Survey. Arch. Gen. Psychiatry 51, 8-19.

Kremers, S.P., Mudde, A.N., de Vries, H., 2001. "Kicking the initiation": do adolescent exsmokers differ from other groups within the initiation continuum? Prev. Med. 33, 392-401.

Leung, R.K., Toumbourou, J.W., Hemphill, S.A., 2014. The effect of peer influence and selection processes on adolescent alcohol use: a systematic review of longitudinal studies. Health Psychol. Rev. 8, 426-457.

McGrath, J.J., Alati, R., Clavarino, A., Williams, G.M., Bor, W., Najman, J.M., Connell, M., Scott, J.G., 2015. Age at first tobacco use and risk of subsequent psychosis-related outcomes: a birth cohort study. Aust. Nz. J. Psychiatry 0004867415587341.

Monshouwer, K., Van Dorsselaer, S., Verdurmen, J., Ter Bogt, T., De Graaf, R., Vollebergh, W., 2006. Cannabis use and mental health in secondary school children. Br. J. Psychiatry 188, 148-153.

Moore, T.H., Zammit, S., Lingford-Hughes, A., Barnes, T.R., Jones, P.B., Burke, M., Lewis, G., 2007. Cannabis use and risk of psychotic or affective mental health outcomes: a systematic review. Lancet 370, 319-328.

Muthén, L.K., Muthén, B., 2010. Mplus: Muthén and Muthén.

Power, R.A., Verweij, K.J., Zuhair, M., Montgomery, G.W., Henders, A.K., Heath, A.C. Madden, P.A., Medland, S.E., Wray, N.R., Martin, N.G., 2014. Genetic predisposition to schizophrenia associated with increased use of cannabis. Mol. Psychiatry 19, 1201-1204.

Purcell, S., Neale, B., Todd-Brown, K., Thomas, L., Ferreira, M.A., Bender, D., Maller, J., Sklar, P., de Bakker, P.I., Daly, M.J., Sham, P.C., 2007. PLINK: a tool set for wholegenome association and population-based linkage analyses. Am. J. Hum. Genet. 81, $559-575$.

Ripke, S., O'Dushlaine, C., Chambert, K., Moran, J.L., Kahler, A.K., Akterin, S., Bergen, S.E., Collins, A.L., Crowley, J.J., Fromer, M., Kim, Y., Lee, S.H., Magnusson, P.K., Sanchez, N., Stahl, E.A., Williams, S., Wray, N.R., Xia, K., Bettella, F., Borglum, A.D., Bulik-Sullivan, B.K., Cormican, P., Craddock, N., de Leeuw, C., Durmishi, N., et al., 2013. Genome-wide association analysis identifies 13 new risk loci for schizophrenia. Nat. Genet. 45, 1150-1159.

Schubart, C., Van Gastel, W., Breetvelt, E., Beetz, S., Ophoff, R., Sommer, I., Kahn, R.S., Boks, M.P., 2011. Cannabis use at a young age is associated with psychotic experiences. Psychol. Med. 41, 1301-1310.

Sherva, R., Wang, Q., Kranzler, H., Zhao, H., Koesterer, R., Herman, A., Farrer, L.A., Gelernter, J., 2016. Genome-wide association study of cannabis dependence severity, novel risk variants, and shared genetic risks. JAMA Psychiatry 73, 472-480.

Simons-Morton, B.G., Farhat, T., 2010. Recent findings on peer group influences on adolescent smoking. J. Prim. Prev. 31, 191-208.

Stringer, S., Minică, C.C., Verweij, K.J.H., Mbarek, H., Bernard, M., Derringer, J., van Eijk, K.R., Isen, J.D., Loukola, A., Maciejewski, D.F., Mihailov, E., van der Most, P.J., Sánchez-Mora, C., Roos, L., Sherva, R., Walters, R., Ware, J.J., Abdellaoui, A., Bigdeli, T.B., Branje, S.J.T., Brown, S.A., Bruinenberg, M., Casas, M., Esko, T., GarciaMartinez, I., Gordon, S.D., et al., 2016. Genome-wide association study of lifetime cannabis use based on a large meta-analytic sample of 32330 subjects from the International Cannabis Consortium. Transl. Psychiatry 6, e769.

Sullivan, P.F., Kendler, K.S., Neale, M.C., 2003. Schizophrenia as a complex trait: evidence from a meta-analysis of twin studies. Arch. Gen. Psych. 60, 1187-1192.

Tobacco and Genetics Consortium, 2010. Genome-wide meta-analyses identify multiple loci associated with smoking behavior. Nat. Genet. 42, 441-447.

van Dorsselaer, S., Tuithof, M., Verdurmen, J., Spit, M., van Laar, M., Monshouwer, K., 2016. Jeugd En Riskant Gedrag. Cijfers En Trends Uit Het Peilstationsonderzoek 2015 [Youth and Risk Behavior. Numbers and Trends from Sentinel Research 2015]. Trimbos Institute, Utrecht, The Netherlands.

van Gastel, W.A., Wigman, J.T., Monshouwer, K., Kahn, R.S., van Os, J., Boks, M.P., Vollebergh, W.A., 2012. Cannabis use and subclinical positive psychotic experiences in early adolescence: findings from a Dutch survey. Addiction 107, 381-387.

van Gastel, W., MacCabe, J., Schubart, C., Vreeker, A., Tempelaar, W., Kahn, R., Boks, M.P., 2013. Cigarette smoking and cannabis use are equally strongly associated with psychotic-like experiences: a cross-sectional study in 1929 young adults. Psychol. Med. 43, 2393-2401.

Van Laar, M., Cruts, A., van Ooyen-Houben, M., Meijer, R., Croes, E., Ketelaars, E., van der Pol, P.M., 2013. Nationale Drug Monitor. Trimbos-instituut. https://www. trimbos.nl/kerncijfers/nationale-drug-monitor/.

Vaucher, J., Keating, B.J., Lasserre, A.M., Gan, W., Lyall, D.M., Ward, J., Smith, D.J., Pell, J.P., Sattar, N., Pare, G., Holmes, M.V., 2017. Cannabis use and risk of schizophrenia: a Mendelian randomization study. Mol. Psychiatry 23, 1287-1292.

Verdurmen, J., Monshouwer, K., van Laar, M., 2014. Roken Jeugd Monitor, 2013 [Smoking Youth Monitor 2013]. Trimbos Institute, Utrecht.

Verweij, K.J., Zietsch, B.P., Lynskey, M.T., Medland, S.E., Neale, M.C., Martin, N.G., 
Boomsma, D.I., Vink, J.M., 2010. Genetic and environmental influences on cannabis use initiation and problematic use: a meta-analysis of twin studies. Addiction 105, 417-430.

Verweij, K.J., Abdellaoui, A., Nivard, M.G., Cort, A.S., Ligthart, L., Draisma, H.H., Minica, C.C., International Cannabis Consortium, Gillespie, W.G., Hottenga, J.J., Boomsma, D.I., Vink, J.M., 2017. Genetic association between schizophrenia and cannabis use.
Drug Alcohol Depend. 171, 117-121.

Walters, J.T.R., Owen, M.J., 2016. Genome-wide significant associations for cannabis dependence severity relevance to psychiatric disorders. JAMA Psychiatry 73, 443-444.

Willett, J.B., Sayer, A.G., 1994. Using covariance structure analysis to detect correlates and predictors of individual change over time. Psychol. Bull. 116, 363. 